\title{
DESIGN AND CALCULATIONS OF A CENTRE LOCKNUT / MONO-LUG WHEEL
}

\section{ASSEMBLY}

\section{MEHER DEV GUDELA, VIRAJ SHAH \& ISHAAN MAURYA}

Undergraduate Student, Department of Mechanical Engineering, Dwarkadas Jivanlal Sanghvi College of

\author{
Engineering, Mumbai, India
}

\begin{abstract}
A wheel assembly is basically a sub-assembly of the suspension system that would link the tires to the chassis through the double wishbone A-arms provide a mounting point for the tires and act as the load bearing component at the wheels. A wheel assembly comprises of the upright, hub, wheel center and lugs. The major difference between the mono-lug wheel assembly and the tri-lug or quad-lug wheel assembly is the number of lug bolts and nuts that are used for a secure mounting of the tires. The main aim of this thesis is to provide the proper calculations and design analysis for a compliance free monolug wheel assembly while comparing it to a traditional trilug wheel assembly. The weight of this monolug assembly is 977.5 which correspond to a direct $12 \%$ reduction of weight when compared to traditional trilug assembly which weighs in at $1112.59 \mathrm{~g}$ as found from the previous wheel assembly designs of our formula student vehicle assemblies. The following mono-lug wheel assembly is being used in DJS Racing's electric vehicle for the 2020 season, DJSR E02. All calculations done in this thesis are in co-ordination with the rules laid out in the FSG 2020 rulebook.

KEYWORDS: Upright; Hub; Wheel Assembly; Mono-Lug, Suspension Geometry; Topology; Vehicle Dynamics
\end{abstract}

Received: Jun 08, 2020; Accepted: Jun 28, 2020; Published: Aug 21, 2020; Paper Id.: IJMPERDJUN2020852

\section{INTRODUCTION}

Formula student competitions require the participants at an international university-level to analyze, design and manufacture a formula-style single seater race car that would compete in various static and dynamic events. The main aim of the competition is to design a single seater race car that is reliable and can be optimized to reach high speed levels. The major part of these vehicles is the vehicle dynamics. Vehicle dynamics mainly govern the performance of the vehicle along the race track, guiding it through straights and corners of the track. ${ }^{[5]}$ Aerodynamics, suspension, steering, brakes and chassis combine to constitute the vehicle dynamics of a race car. The tires of a race car are considered to beof the most important components of the vehicle as it is the only point of contact between the car and the ground. ${ }^{[1]}$ Oftentimes a poorly designed wheel assembly that doesn't take into account the camber, caster, kingpin or scrub radius can be the difference between a sluggish car that struggles to clear the dynamic events and a competition winning race car.

Wheel assembly is one of the most important components of a race car as it acts the mounting point of the tires and the load bearing component at the tires.It is the component that links the tires of the vehicle to the main chassis frame of the car. Wheel assemblies of a formula student race car are usually linked to the chassis through double wishbone structures known as A-arms.

The Main Wheel Assembly Constitutes of

- Upright 
- Hub

- Wheel Center

- $\quad$ Lugs(Bolts and Nuts)

The wheel center is mounted at the tire rims and the tiresare then mounted on the lugs through the wheel center. These lugs are in turn attached to the hub which is press-fitted through the bore on the upright. The lugs are tightening fasteners which ensure the secure mounting of tires to the wheel assembly. Based on the number of lugs used in the mounting of a tire, a wheel assembly can be categorized as a multi-lug wheel assembly (tri-lug or quadlug) and mono-lug wheel assembly. The major difference between mono-lug wheel assembly and multi-lug wheel assembly is that in the former there is one bolt in the center of the rim followed by a locking nut instead of multiple lug bolts placed around the center of the rim. ${ }^{[2]}$

\section{DESIGN GOALS}

- $\quad$ Reducing the overall weight of the wheel assembly that would in turn reduce the overall unsprung mass.

- Obtaining optimized camber curves to ensure maximum traction at the loaded wheel.

- Having a mono-lug wheel assembly would help in eliminating uneven tightening torque as found when having multiple lugs in the multi-lug wheel assembly.

- To reduce the complex and time-consuming process of tightening of multiple lug bolts by replacing it with a single lug bolt.

- To increase power by weight ratio by decreasing the weight of all four-wheel assemblies of the vehicle.

- To design an assembly that would increase the maintainability and serviceability of the wheel assembly.

\section{DESIGN PROCEDURE}

- A virtual suspension line geometry is made using the Lotus software that is used to calculate the dimensions of the upright and hub with considerations made on the camber, caster and kingpin inclination. ${ }^{[6]}$

- $\quad$ Figure 1 shows the final 2D suspension line geometry is made on the LOTUS software based on which the entire suspension components are designed.

- $\quad$ Figure 2 shows the entire wheel assembly is designed with three main objectives in mind.

- Weight Reduction.

- Increasing the reliability of the components.

- Increase

- $\quad$ sing the efficiency of manufacturing and thus reducing the offsets or errors produced. ${ }^{[1]}$ 


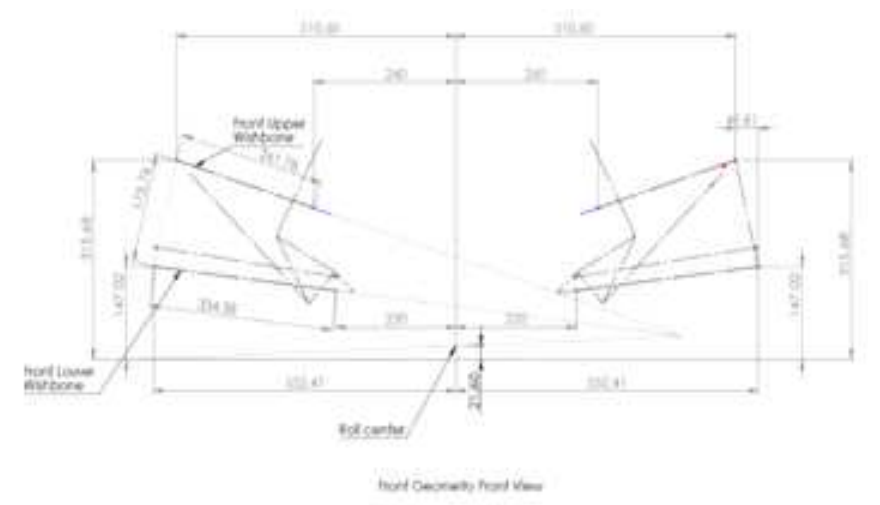

Figure 1: Front Geometry Front View.

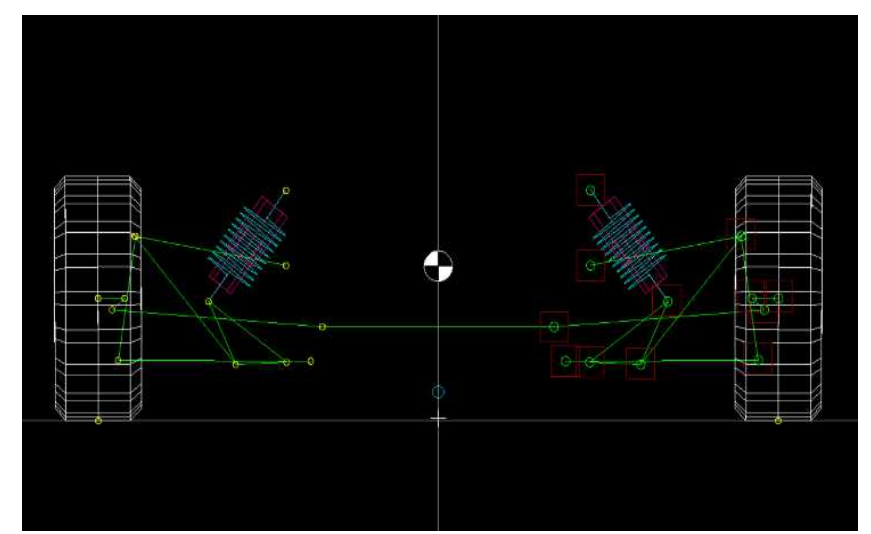

Figure 2: Front Geometry Simulation on LOTUS.

\section{DESIGN}

The entire wheel assembly is designed with three main objectives in mind.

- Weight Reduction.

- Increasing the reliability of the components.

- Increasing the efficiency of manufacturing and thus reducing the offsets or errors produced. ${ }^{[2]}$

\subsection{Hub}

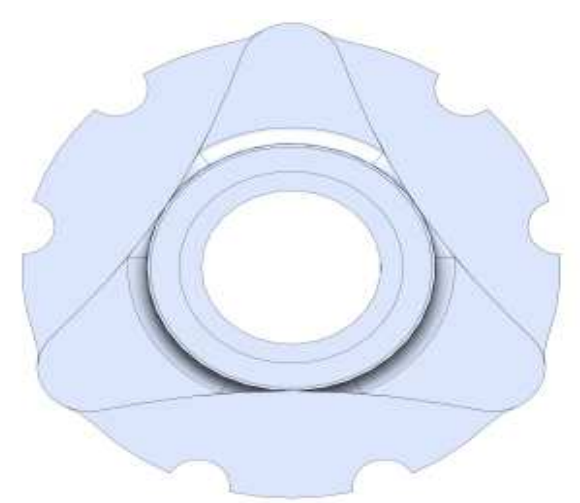

Figure 3: Front View. 


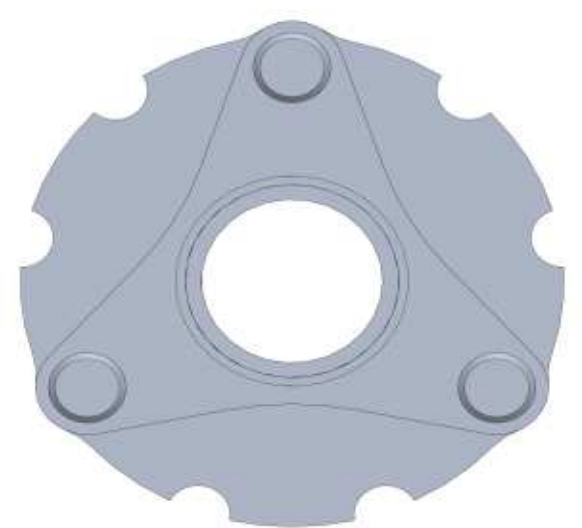

Figure 4: Rear View.

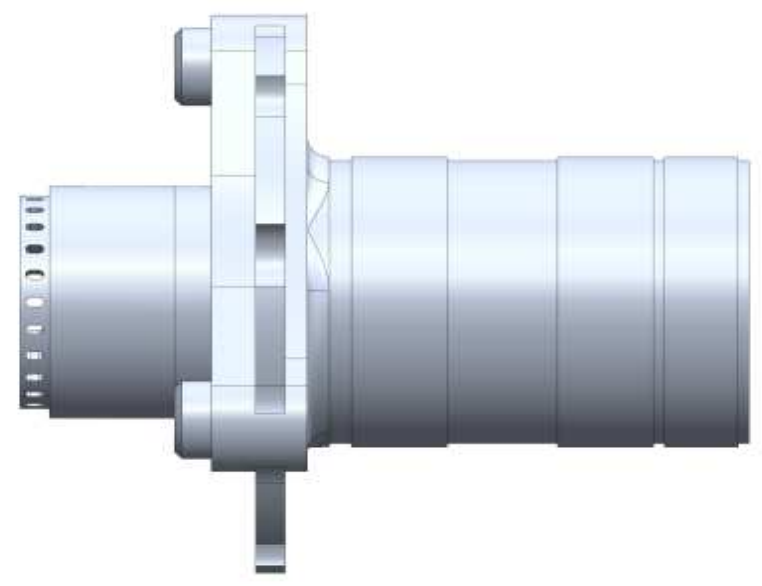

Figure 5: Side View.

\subsection{Upright}

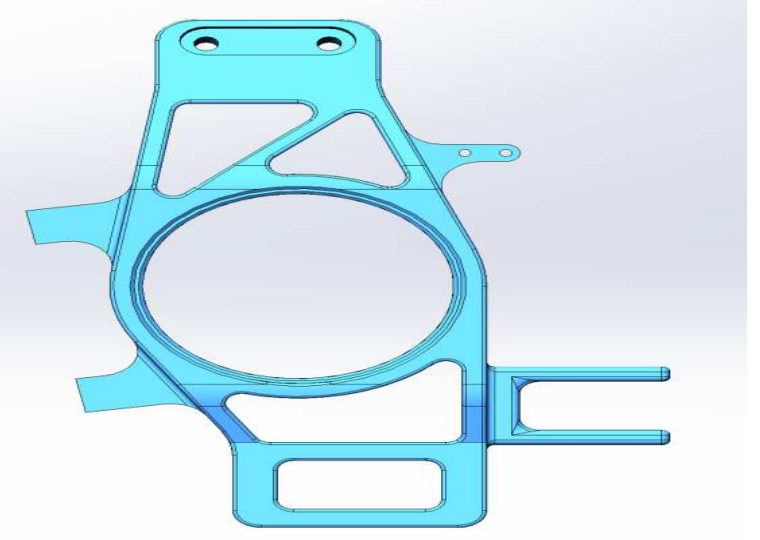

Figure 6: Front View. 


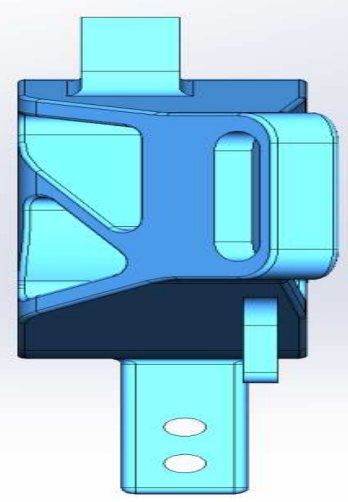

Figure 7: Top View.

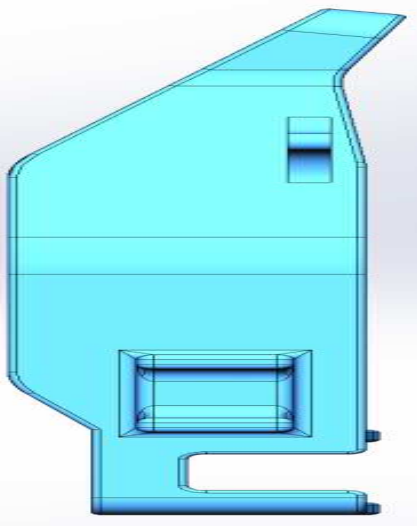

Figure 8: Side View.

\section{ANALYSIS}

Force Analysis was done on the ANSYS software to check how the components work under stress and the deformations that occur at certain points on the components at definite loads using constraints placed at ideal positions.

\subsection{Hub}

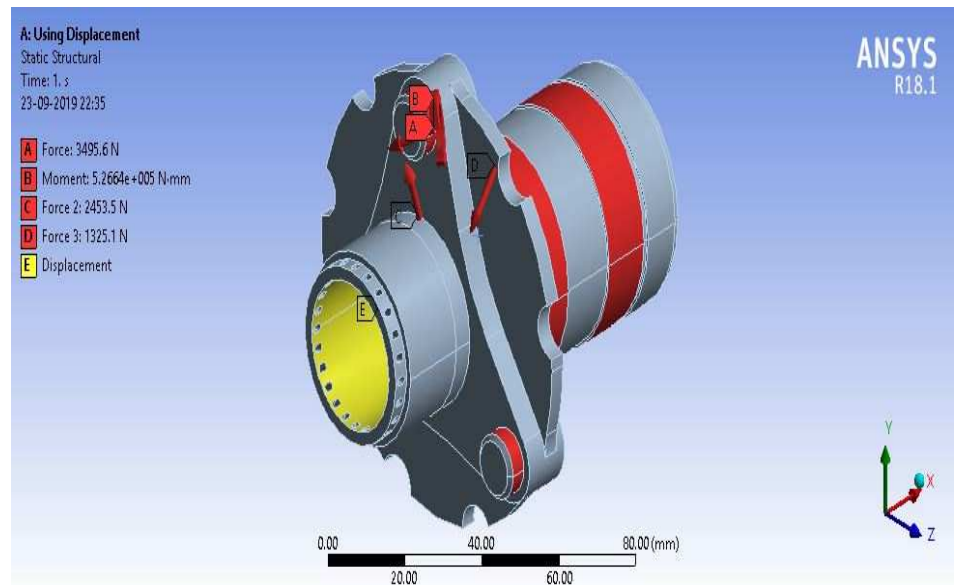

Figure 9: Forces Diagram. 


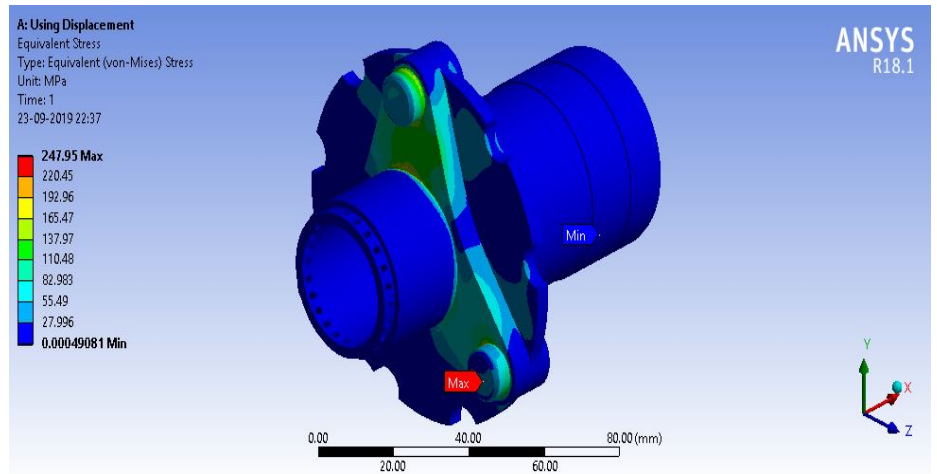

Figure 10: Stress Analysis.

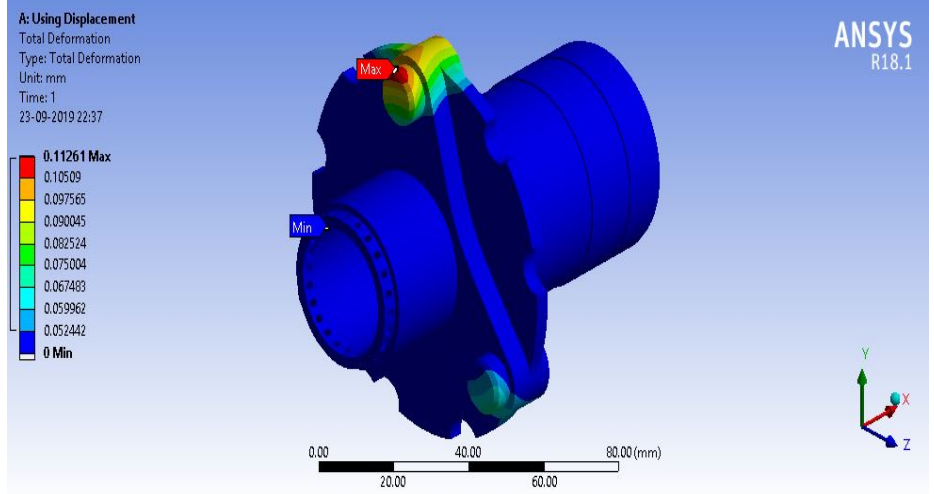

Figure 11: Total Deformation.

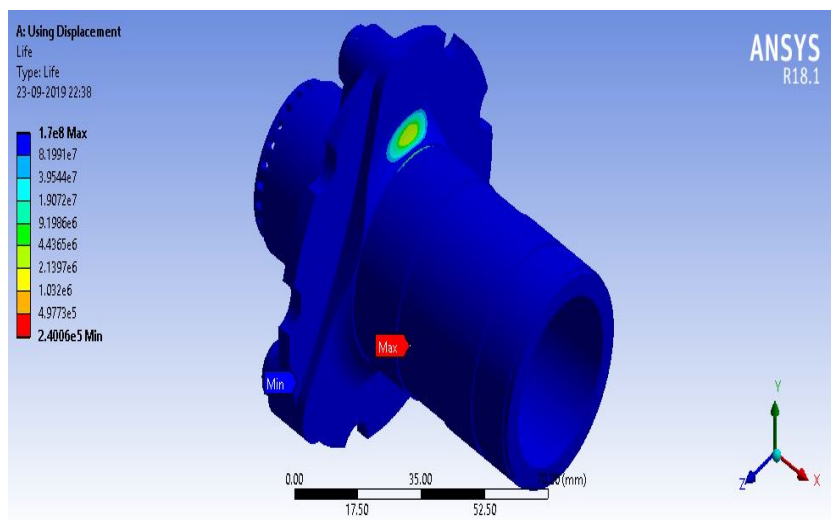

Figure 12: Fatigue Life.

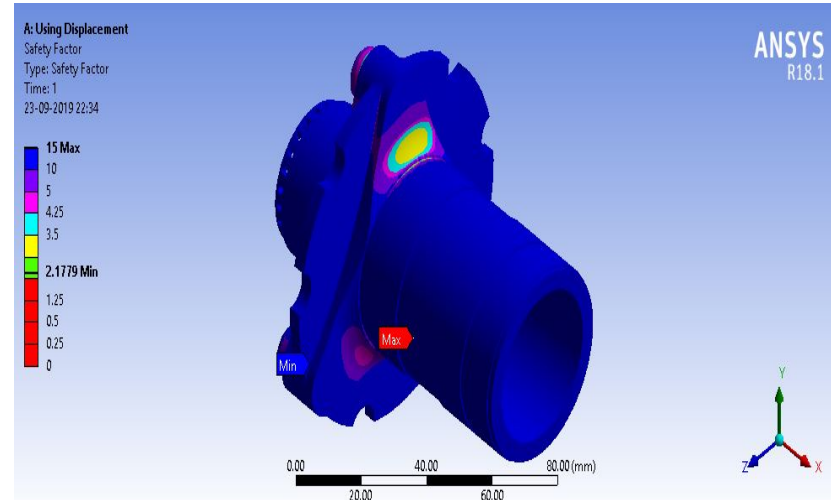

Figure 13: Safety Factor. 


\subsection{Upright}

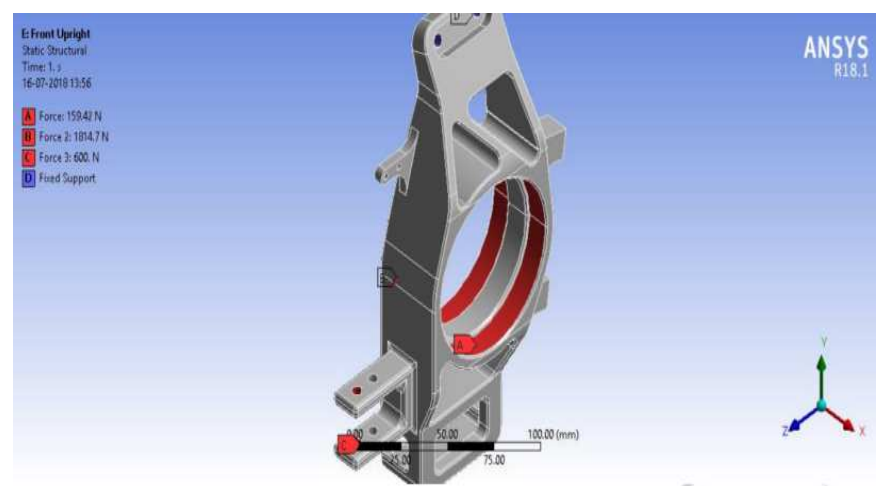

Figure 13: Forces Diagram.

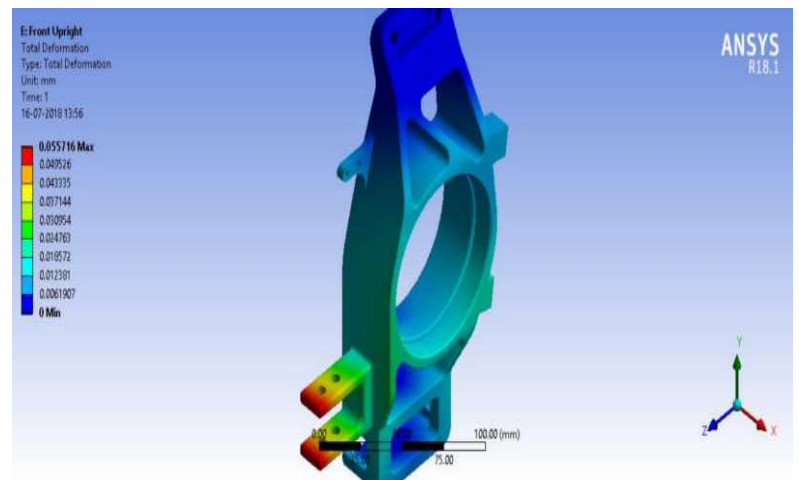

Figure 14: Deformation.

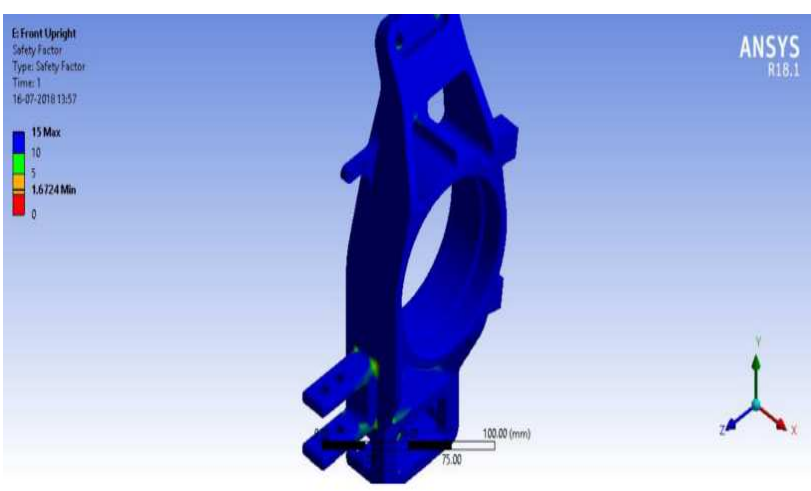

Figure 15: Factor of Safety.

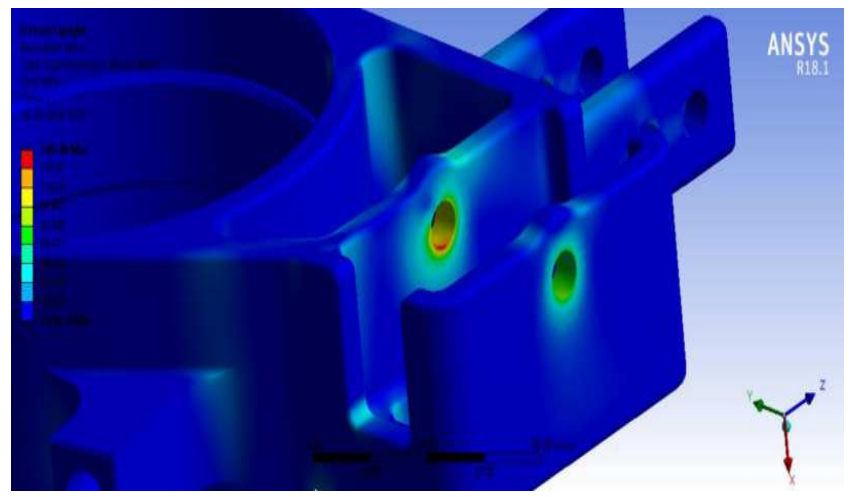

Figure 16: Stress. 


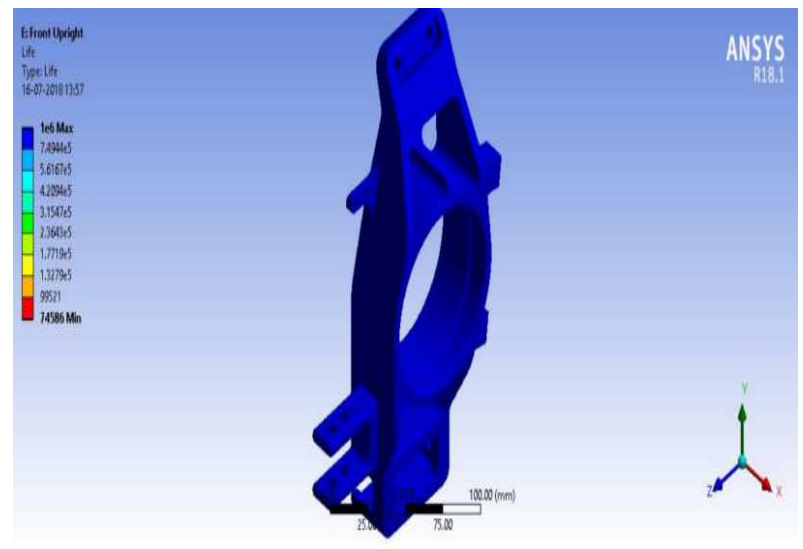

Figure 17: Fatigue Life.

\section{CALCULATIONS}

The calculations for a mono-lug wheel assembly are done to obtain the minimum and maximum tightening torque as well as shear safety factor.

All these calculations are based on our 2019 Combustion Vehicle DJSR 05.

Total weight of car with driver $=260 \mathrm{~kg}(573.202 \mathrm{lb})$

Weight Distribution (Front:Rear) $=0.5048: 0.4952$

Weight on front axle $=131.248 \mathrm{~kg}$

Weight on rear axle $=128.752 \mathrm{~kg}$

Static weight on front tire $=65.624 \mathrm{~kg}$

Static Weight on rear tire $=64.376 \mathrm{~kg}$

Wheelbase $=1650 \mathrm{~mm}$

Front Trackwidth $=1200$

Rear Trackwidth $=1200 \mathrm{~mm}$

CG Height $=242.613 \mathrm{~mm}$

Longitudinal Acceleration $=1.6 \mathrm{~g}$

Lateral Acceleration $=1.4 \mathrm{~g}$

\section{Calculating Maximum Normal Force on Rear outside Wheel:}

- Longitudinal Weight Transfer To Rear

$$
\begin{gathered}
\frac{\text { TotalWeig } \square t * \text { LongitudinalAcceleration } * \text { CGHeig } \square t}{W \square \text { eelbase }} \\
\frac{260 * 1.6 * 242.613}{1650}
\end{gathered}
$$

$=61.168 \mathrm{~kg}$ 
- Lateral Weight Transfer

$$
\begin{gathered}
\frac{\text { Totalweig } \square t * \text { LateralAcceleration } * \text { CGHeig } \square t}{\text { Trackwidt } \square} \\
\frac{260 * 1.6 * 242.613}{1200}
\end{gathered}
$$

$=73.593 \mathrm{~kg}$

- Maximum Normal Force on Rear Outside Wheel

Static load on single rear wheel $+\frac{\text { Longitudinalweig } \square \text { ttransfer }+ \text { Lateralweig } \square \text { ttransfer }}{2}$

$$
\begin{aligned}
& 64.376+\frac{61.168+73.592}{2} \\
& 64.376+67.380 \\
& =131.756 \mathrm{~kg} \\
& =1292.526 \mathrm{~N}
\end{aligned}
$$

- Maximum Normal Force on Rear outside Wheel Including Aerodynamic Down Force

$1292.526+65$

$=1357.526 \mathrm{~N}$

Coefficient of friction $=2.35$

Radius of Rim=127 mm

Radius of $\mathrm{Hub}=36.5 \mathrm{~mm}$

Calculating Lateral Force on Hub:

- Lateral Force On Hub

Maximumnormalload $*$ Coefficientoffriction $*$ RadiusofRim
$\frac{\text { Radiusof Hub }}{36.5}$

\section{Calculating Bolt Dimensions:}

Nominal Diameter $=36 \mathrm{~mm}$

$\operatorname{Pitch}(\mathrm{p})=2 \mathrm{~mm}$

- $\quad$ Core Diameter $\left(\mathbf{D}_{\mathrm{C}}\right)$

Nominal Diameter - $(1.22687 * p)$

$36-(1.22687 * 2)$ 
$=33.546 \mathrm{~mm}$

- $\quad$ Flank Diameter $\left(D_{\mathbf{P}}\right)$

Nominal Diameter - $(0.6492 * \mathrm{p})$

$36-(0.6492 * 2)$

$=34.702 \mathrm{~mm}$

c) Mean Diameter (D)

$$
\frac{\mathrm{Dc}+\mathrm{Dp}}{2}
$$$$
\frac{33.546+34.702}{2}
$$

$=34.124 \mathrm{~mm}$

Internal diameter $(\mathrm{d})=32 \mathrm{~mm}$

Tensile Yield Strength $=480$ N//mm2

Factor of Safety $=3$

Allowable Tensile Stress $=160$ N/mm2

\section{CalculatingInduced Tensile Stress:}

- $\quad$ Tensile Area

$$
\begin{gathered}
\frac{\pi *\left[D^{2}-d^{2}\right]}{4} \\
\frac{\left.\pi *\left[(34.124)^{2}-(32)^{2}\right)\right]}{4}
\end{gathered}
$$

$=110.307 \mathrm{~mm}^{2}$

- Induced Tensile Stress

$$
\begin{gathered}
\frac{\text { TensileForce }}{\text { TensileArea }} \\
\frac{11100.100}{110.307}
\end{gathered}
$$

$=100.629 \mathrm{~N} / \mathrm{mm} 2$

Since the induced tensile stress $(100.629 \mathrm{~N} / \mathrm{mm} 2)$ is less than the allowable tensile stress $(160 \mathrm{~N} / \mathrm{mm} 2)$, the design is safe in tension.

Shear Strength=331 N//mm2

Factor of Safety $=3$

Allowable Shear Stress $=110.33$ N/mm2 


\section{Calculating Induced Shear Stress:}

- Shear Area

$$
\begin{gathered}
\frac{\pi *\left[D^{2}-d^{2}\right]}{4} \\
\frac{\left.\pi *\left[(34.124)^{2}-(32)^{2}\right)\right]}{4}
\end{gathered}
$$

$=110.307 \mathrm{~mm}^{2}$

- Induced Shear Stress

$$
\begin{gathered}
\text { MaximumLoadonRearOutsideW } \square \text { eel } \\
\frac{1357.526}{110.307}
\end{gathered}
$$

$=12.307 \mathrm{~N} / \mathrm{mm}^{2}$

Since the induced shear stress $\left(12.307 \mathrm{~N} / \mathrm{mm}^{2}\right)$ is less than the allowable tensile stress $\left(110.33 \mathrm{~N} / \mathrm{mm}^{2}\right)$, the design is safe in tension.

Nut Factor $=0.26$

Axial Force $=11100.1 \mathrm{~N}$

Nominal Diameter $=36 \mathrm{~mm}$

Ultimate Tensile Strength $=503 \mathrm{~N} / \mathrm{mm}^{2}$

Factor of Safety $=3$

Maximum Allowable Tensile Stress $=167.667$ N/mm 2

\section{Calculating Tightening Torque:}

- Minimum Tightening Torque

Nut Factor*Axial Force*Nominal Diameter

$0.26 * 11100.1 * 36$

$=103896.936 \mathrm{~N}-\mathrm{mm}$

- Maximum Axial Force

Maximum Allowable Tensile Stress*Tensile Area

$167.6678 * 110.307$

$=18494.807 \mathrm{~N}$

- Maximum Tightening Torque

Nut Factor*Maximum Axial Force*Nominal Diameter 
$0.26 * 18494.807 * 36$

$=173111.394 \mathrm{~N}-\mathrm{mm}$

\section{CONCLUSIONS}

A wheel assembly carries the entire load at the point of contact of vehicle to the ground. Hence, this thesis displays the optimum design of a mono-lug wheel assembly and the calculations required to classify the mono-lug design as safe and durable. Apart from the design, the analysis of the mono-log design shows the various loads the mono-lug assembly will concur and its sustainability during its application in our 2019 Combustion Race Car DJSR05. While this design hasn't been tested yet, we believe, through the design and analysis of this wheel assembly, we can achieve higher efficiency on our overall vehicle design while reducing the overall weight of the car.

\section{REFERENCES}

1. Milliken \& Milliken, "Race Car vehicle dynamics", SAE International, 1995, ISBN I-56091-526-9.

2. Carroll Smith, “Tune TO Win”, Aero Publisher,Inc, 1978, ISBN 0-87938-071-3.

3. Carroll Smith, “Engineering TO Win”, Aero Publisher, Inc, 1978, ISBN 87938-071-3.

4. http://www.fsae.com/forums/forum.php

5. Andrew Wong, "Design and optimization of uprightassemblies for Formula Student Race car", Department of Mechanical Engineering,University of Toronto, March 2007.

6. John Dixon, “Suspension Geometry and computation”, ISBN-13: 978-0470510216.

7. Phadke, Vaibhav, and Nikhil Titirmare."Construction of Tunnels, by New Austrian Tunneling Method (NATM) and by Tunnel Boring Machine (TBM)." International Journal of Civil Engineering (IJCE) 6.6 (2017): 2536.

8. Thomas D. Gillespie, “Fundamentals of VehicleDynamics”, ASIN: B07Z8HILT3.

9. Biswal, Sadjyot\&Prasanth, Aravind\&Udayakumar, R. \& Deva, Shobhit\& Gupta, Aman. (2017). Design of a suspension system and determining suspension parameters of a medium downforce small Formula type car. MATEC Web of Conferences. 124. 07006. 10.1051/matecconf/201712407006.

10. RAO, POTHAMSETTY KASI V. "Design of stair-climbing wheelchair using tri-wheel mechanism." International Journal of Mechanical and Production Engineering Research and Development 8.4 (2018): 685694.

11. Mahadik, Sameer. (2018). Design and ANSYS analysis of Components of Wheel Assembly of SAE Car. International Journal of Current Engineering and Technology. 8. 10.14741/ijcet/v.8.2.36.

12. Rajavel, Ponshanmugakumar. (2018). Design and Analysis of Wheel Hub for Student Formula Car. International Journal of Mechanical and Production Engineering Research and Development. 8. 811-816. 10.24247/ijmperdfeb201893.

13. Joy, N. I. V. I. N. "Design and Analysis of an Integrated Exhaust Manifold with Turbocharger for Considerable Reduction of Over Heating of Bearing System." International Journal of Mechanical and Production Engineering Research and Development 8.2 (2018): 601608.

14. Azmeer, M \&Basha, MohdHafif\& Hamid, MohdFadzli\& Abdul Rahman, Md \& Mohamad Hashim, Mohd Sani. (2017). Design optimization of rear uprights for UniMAP Automotive Racing Team Formula SAE racing car. Journal of Physics: Conference Series. 908. 012051. 10.1088/1742-6596/908/1/012051. 
15. Suresh Bade Venkata, et al. "FABRICATION OF COMBINED IN-PHASE AND COUNTER-PHASE STEERING MECHANISM OF A FOUR WHEEL DRIVE." International Journal of Engineering, Science and 6 (2017): 401-415.

16. Kakria, S. \& Singh, D.. (2015). CAE Analysis, Optimization and Fabrication of Formula SAE Vehicle Structure. 2015. 10.4271/2015-01-0072. 

